Supporting Information

\title{
Size-Shifting Micelle Nanoclusters Based on a Cross-Linked and pH-Sensitive Framework for Enhanced Tumor Targeting and Deep Penetration Features
}

Huihui Liang, Xiaoqing Ren, Jianghui Qian, Xiulei Zhang, Lin Meng, Xiaofei Wang, Lei Li, Xiaoling Fang, and Xianyi Sha*

Key Laboratory of Smart Drug Delivery, Ministry of Education \& PLA, School of Pharmacy, Fudan University, Lane 826, Zhangheng Road, Shanghai 201203, China

*Corresponding author. Phone/fax: +86-21-51980072.

E-mail: shaxy@fudan.edu.cn 


\section{In vitro release profile}

In vitro release behavior of PM and PMNC was investigated by dialysis method. ${ }^{1}$ Briefly, $1 \mathrm{~mL}$ of PM solution or PMNC solution (containing $0.2 \mathrm{mg}$ PTX) was added to the pre-swollen dialysis bag (MWCO $=3500 \mathrm{Da}$, Greenbird Inc., Shanghai, China), and then the dialysis bag with sealed ends was submerged fully into $49 \mathrm{~mL}$ of PBS $(\mathrm{pH} 5.0,0.01 \mathrm{M})$ or PBS $(\mathrm{pH} 7.4,0.01 \mathrm{M})$ containing $0.5 \%$ Tween 80 to reach pseudosink conditions. The dialysis was carried out at $37^{\circ} \mathrm{C}$ with oscillation at 100 rpm for $24 \mathrm{~h}$. The concentration of PTX in samples was analyzed by HPLC with revision for volume replacement. PTX release from PTX stock solution was determined by the same method as a control.

PBS ( $\mathrm{pH} 7.4,0.01 \mathrm{M}$ ) medium (A) was used for stimulating the physiological $\mathrm{pH}$ and PBS (pH 5.0, $0.01 \mathrm{M}$ ) medium was for lysosomal acidity. ${ }^{2}$ As shown in Figure S1, in both PBS (pH 7.4, $0.01 \mathrm{M})$ and PBS (pH 5.0, $0.01 \mathrm{M}$ ) medium, nearly $100 \%$ of the PTX in a stock solution was released into receiving solution within the first $2 \mathrm{~h}$, indicating that PTX could freely diffuse through dialysis bag. In pH 7.4 conditions, almost all the PTX in PM was released within $10 \mathrm{~h}$, while only about $50 \%$ of PTX in PMNC was released at the same time, significantly slower than that of PM group $(p<$ 0.01). This result suggested that PMNC had certain sustained release effect in physiological $\mathrm{pH}$, which might be caused by cross-linked framework as it could hamper the release of micelles. Compared with the release profile in $\mathrm{pH} 7.4 \mathrm{PBS}$, the release of PTX from PM in pH 5.0 condition did not change significantly and completely released within $10 \mathrm{~h}$. However, the release speed of PMNC group in $\mathrm{pH}$ 5.0 PBS was significantly higher than that of $\mathrm{pH} 7.4$ PBS. The release behavior of PMNC group in pH 5.0 condition was consistent with the PM group because PMNC exhibited as independent micelles after the cross-linked framework being damaged under acidic conditions. The cumulative PTX release of PMNC got nearly to that of PM since $6 \mathrm{~h}$ and PTX was completely released from PMNC at $12 \mathrm{~h}$. 
A

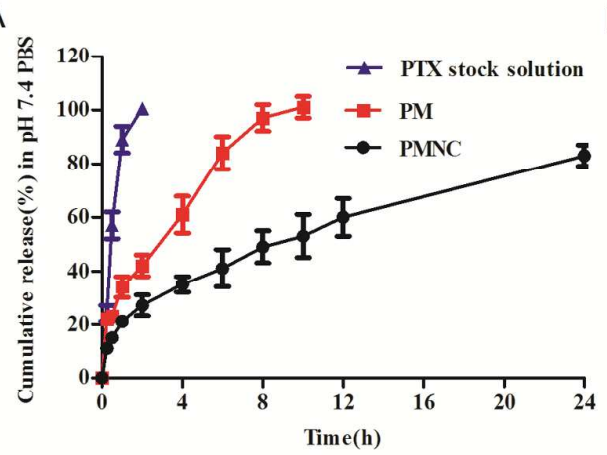

$B$

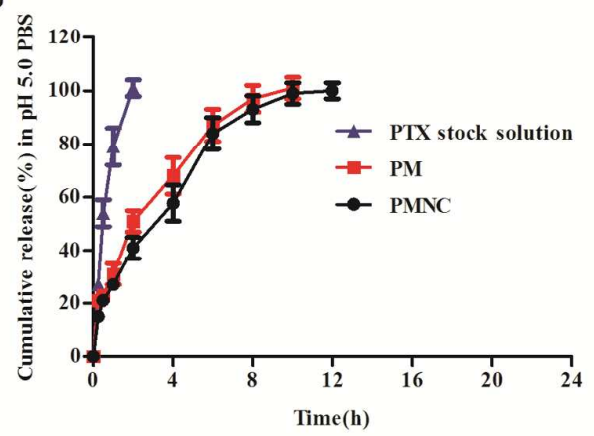

Figure S1. Release profiles of PTX from micelles in PBS (pH 7.4, 0.01 M) (A) and PBS (pH 5.0, $0.01 \mathrm{M})(\mathrm{B})$ at $37^{\circ} \mathrm{C}$.

\section{Cellular uptake}

A549 and RAW264.7 cells line in logarithmic growth phase were seeded in 24-well plates at the density of approximately $1 \times 10^{5}$ cells/well. $24 \mathrm{~h}$ later, CM and CMNC in corresponding medium without FBS were added to each well with the concentration of $100 \mu \mathrm{g} / \mathrm{mL}$ and $1000 \mu \mathrm{g} / \mathrm{mL}$, followed by incubation at $37^{\circ} \mathrm{C}$ for $30 \mathrm{~min}, 1 \mathrm{~h}, 2 \mathrm{~h}$ and $4 \mathrm{~h}$, respectively. Then cells were rinsed with cold PBS (0.01 M, pH 7.4) and fixed with $4 \%$ paraformaldehyde. Finally, cells were immediately observed and photographed under a fluorescent microscope (DMI 4000B, Leica, Gremany). For quantitative analysis, different cells were collected by trypsin digestion, suspended in $0.2 \mathrm{~mL}$ PBS (0.01 M, pH 7.4), and then determined by flow cytometry (BD, USA).

The fluorescence intensity shown in Figure S2 revealed that the uptake of CMNC by A549 cells was significantly higher than that of $\mathrm{CM}$ at all detected time. In contrary, the fluorescence intensity of CMNC in RAW264.7 cells was lower than that of CM. Quantitative results shown in Figure S3 were consistent with the qualitative results and revealed the concentration-dependent of cellular uptake by A549 cells and RAW264.7 cells. These results indicated that, compared with CM, CMNC had stronger ability of cellular uptake by A549 cells and escaping the phagocytosis by RAW264.7 cells. 
A549 cells
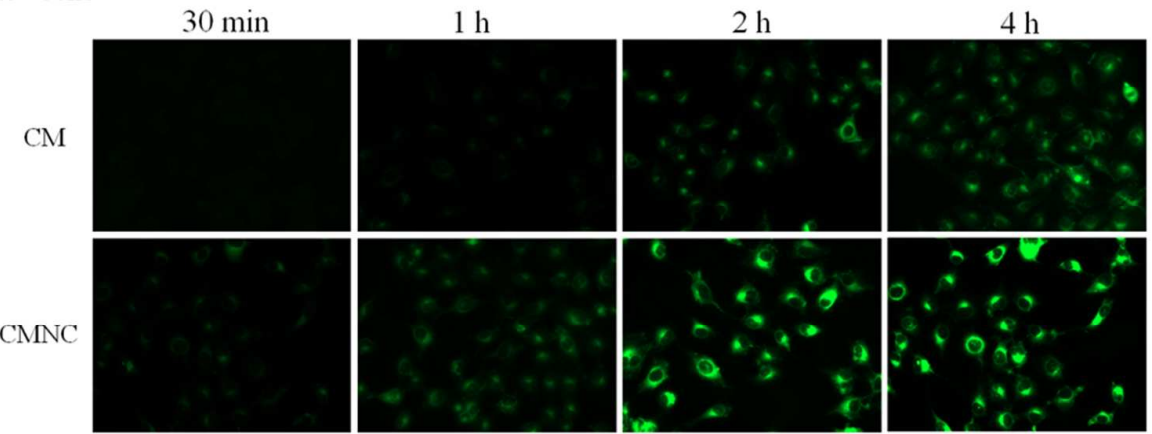

RAW264.7 cells
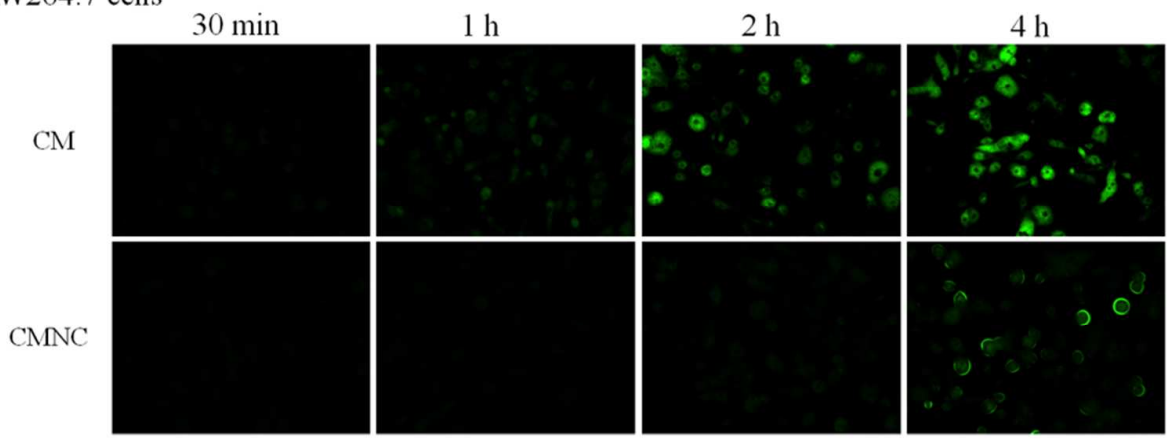

Figure S2. Fluorescent images A549 cells and RAW264.7 cells after incubation with $\mathrm{CM}$ and $\mathrm{CMNC}$ for $30 \mathrm{~min}, 1 \mathrm{~h}, 2 \mathrm{~h}$ and $4 \mathrm{~h}$, respectively.
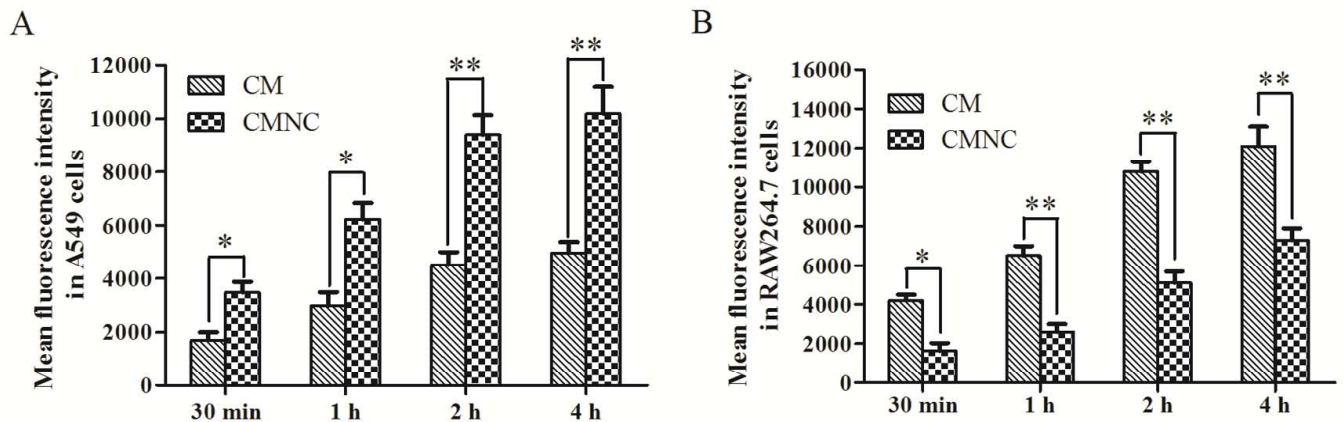

Figure S3. Quantitation of mean fluorescent intensity of coumarin-6 in A549 cells (A) and RAW264.7 cells (B) after culture with $\mathrm{CM}$ and CMNC for $30 \mathrm{~min}, 1 \mathrm{~h}, 2 \mathrm{~h}$ and 4 $\mathrm{h}$, respectively. Data is presented as means $\pm \mathrm{SD}(\mathrm{n}=3) .{ }^{*} p<0.01,{ }^{*} p<0.05$ significantly different with that of CM.

\section{Penetration into cell monolayers}

Table S1. The percentage of coumarin-6 encapsulated in micelles versus the whole amount of coumarin- 6 in lower chambers $(n=3)$ 


\begin{tabular}{ccc}
\hline & A549 cells & HUVEC cells \\
\hline CM & $73.58 \pm 6.71 \%$ & $79.31 \pm 5.80 \%$ \\
CMNC & $76.82 \pm 6.38 \%$ & $81.44 \pm 4.29 \%$ \\
\hline
\end{tabular}

Table S2. The transmembrane ratio of both $\mathrm{CM}$ and CMNC through different cell monolayers $(n=3)$.

\begin{tabular}{ccc}
\hline & A549 cell monolayer & HUVEC cell monolayer \\
\hline $\mathrm{CM}$ & $5.1 \pm 0.8 \%$ & $9.4 \pm 1.9 \%$ \\
$\mathrm{CMNC}$ & $7.3 \pm 0.3 \%$ & $14.6 \pm 1.8 \%$ \\
\hline
\end{tabular}

\section{Pharmacokinetic study}

Twelve SD rats were divided into two groups for pharmacokinetic analysis randomly. PM and PMNC were intravenously injected at an equivalent PTX dose of 3 $\mathrm{mg} / \mathrm{kg}$, respectively. At 5, 15, 30, 60, 90, 120, 180, 240, 360 and $480 \mathrm{~min}$ after injection, $0.2 \mathrm{~mL}$ blood was obtained into heparinized tubes and centrifuged at 10,000 rpm for $10 \mathrm{~min}$, after that plasma could be collected. Then stored the plasma at $-20^{\circ} \mathrm{C}$ before LC-MS/MS (API-3000, Applied Biosystems, USA) analysis. $150 \mu \mathrm{L}$ of docetaxel methanol solution $(100 \mathrm{ng} / \mathrm{mL})$, the internal standard, was mixed with 50 $\mu \mathrm{L}$ plasma to precipitate protein. Then the mixture was centrifuged for $10 \mathrm{~min}$ at $12,000 \mathrm{rpm}$ and $5 \mu \mathrm{L}$ supernatant was transferred for LC-MS/MS analysis. DAS 2.0 was used to calculate the pharmacokinetic parameters and Windows software package was applied for statistics.

PTX was used as the model drug to evaluate the pharmacokinetic behavior of micells and MNC. As shown in Figure S4, the concentration-time curves of PTX after i.v. administration with PM and PMNC at $2.5 \mathrm{mg} / \mathrm{kg}$ dose of PTX. PMNC showed better blood circulation levels than PM during all experimental hours. The related pharmacokinetic parameters calculated by compartmental analysis was listed in Table S1. PMNC achieved much larger area under the curve (AUC) compared to PM. The $\mathrm{AUC}_{0 \rightarrow \infty}$ and $\mathrm{AUC}_{0 \rightarrow \mathrm{t}}$ of $\mathrm{PMNC}$ were $134.76 \pm 25.10$ and 219.03 \pm 52.93 , which was 
5.53 and 7.43 times higher than that of PM, respectively. It was also shown that PMNC could extend the half-life $\left(\mathrm{t}_{1 / 2}\right)$ from $159.55 \pm 35.77$ to $412.93 \pm 120.21 \mathrm{~min}$ ( $p<$ 0.01). Moreover, the mean residence time (MRT) for PMNC, $\mathrm{MRT}_{(0-\mathrm{t})}$ and $\mathrm{MRT}_{(0-\infty)}$, was 1.57-fold and 2.74-fold higher than that of PM $(p<0.01)$, respectly. In contrast, the clearance $(\mathrm{CL})$ and the apparent volume of distribution (V) for PMNC was significantly lower than that of PM, implying a longer retention of the drug in blood circulation $^{3}$. All of these results showed that the PMNC significantly reduced the plasma elimination rate and increased systemic circulation time of PTX.

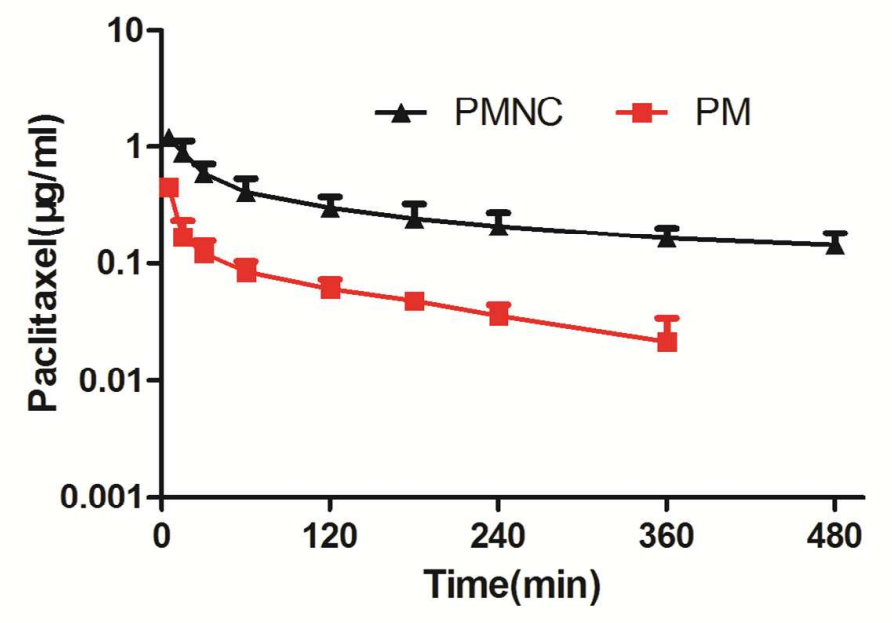

Figure S4. PTX plasma concentration-time curves of PM and PMNC after i.v. administration to SD rats (PTX: $2.5 \mathrm{mg} / \mathrm{kg}$ ). Each point represented average $\pm \mathrm{SD}$ (n $=6)$.

Table S3. Comparative pharmacokinetic parameters of PM and PMNC $(n=6)$.

\begin{tabular}{ccc}
\hline Parameters & PM & PMNC \\
\hline $\mathrm{AUC}_{(0-\mathrm{t})}(\mathrm{mg} / \mathrm{L} * \mathrm{~min})$ & $24.37 \pm 3.17$ & $134.76 \pm 25.10^{* *}$ \\
$\mathrm{AUC}_{(0-\infty)}\left(\mathrm{mg} / \mathrm{L}^{*} \mathrm{~min}\right)$ & $29.47 \pm 4.64$ & $219.03 \pm 52.94^{* *}$ \\
$\mathrm{MRT}_{(0-\mathrm{t})}(\mathrm{min})$ & $104.61 \pm 7.56$ & $164.12 \pm 8.57^{*}$ \\
$\mathrm{MRT}_{(0-\infty)}(\mathrm{min})$ & $190.46 \pm 37.28$ & $521.73 \pm 117.74^{* *}$ \\
$\mathrm{t}_{1 / 2}(\mathrm{~min})$ & $159.55 \pm 35.77$ & $412.93 \pm 120.21^{* *}$ \\
$\mathrm{CL}(\mathrm{L} / \mathrm{min} / \mathrm{kg})$ & $0.087 \pm 0.012$ & $0.012 \pm 0.003^{*}$ \\
& $\mathrm{~s}-6$ &
\end{tabular}




\begin{tabular}{ccc}
$\mathrm{V}(\mathrm{L} / \mathrm{kg})$ & $19.67 \pm 3.75$ & $6.88 \pm 1.367 *$ \\
\hline$* * p<0.01, * p<0.05$ significantly different with that of PM.
\end{tabular}

\section{References}

(1) Chen, Y.; Zhang, W.; Gu, J.; Ren, Q.; Fan, Z.; Zhong, W.; Fang, X.; Sha, X. Enhanced Antitumor Efficacy by Methotrexate Conjugated Pluronic Mixed Micelles against KBv Multidrug Resistant Cancer. Int J Pharm 2013, 452, 421-433.

(2) Xu, P.; Van Kirk, E. A.; Zhan, Y.; Murdoch, W. J.; Radosz, M.; Shen, Y. Targeted Charge-Reversal Nanoparticles for Nuclear Drug Delivery. Angew Chem Int Ed Engl 2007, 46, 4999-5002.

(3) Ueda, K.; Kawaguchi, Y.; Iwakawa, S. Effect of Oxyethylene Numbers on the Pharmacokinetics of Menatetrenone Incorporated in Oil-in-Water Lipid Emulsions Prepared with Polyoxyethylene-Polyoxypropylene Block Copolymers and Soybean Oil in Rats. Biol Pharm Bull 2008, 31, 2283-2287. 